\title{
REMOTE SENSING UAV/DRONE TECHNOLOGY AS A TOOL FOR URBAN DEVELOPMENT MEASURES IN APCRDA
}

\author{
T. Preethi Latha ${ }^{1, *}$, K.NagaSundari $^{1}$, Sreedhar Cherukuri I.A.S ${ }^{1}$, M.V.V.S.V.Prasad ${ }^{1}$ \\ ${ }^{1}$ Andhra Pradesh Capital Region Development Authority (APCRDA), Municipal Administration and \\ Urban Development (MA\&UD), Govt. of Andhra Pradesh, India - pritlata1309@ gmail.com*, \\ nagasundari.k@apcrda.org, sreedhar.cherukuri@apcrda.org,marni.prasad@apcrda.org
}

Commission VI, WG VI/4

KEY WORDS: Remote Sensing, UAV/Drone, Buildings occupancy, Urban Development, Planning, Smart Cities

\begin{abstract}
:
Now-a-days, collecting accurate and meaningful information about the urban localities/environment with the maximum efficiency in terms of cost and time has become more relevant for urban, rural and city level development planning and administration. This work presents a technical procedure for automatic extraction of building information and characterization of different urban building types within the Andhra Pradesh Capital Region Development Authority (APCRDA) jurisdiction areas using UAVs. The methodology consists of a number of sequential processes of acquisition and generation of high resolution Orthomosaic images, creation of 3D point cloud data, and image classification algorithm for feature extraction using exclusively the geometric coordinates. The main parameters of the urban structures/buildings assessed in this work are site area of the building, built-up area, and building dimensions, building setbacks and building height. Different geometric and appropriate metrics were automatically extracted for each of the elements, defining the urban typology. In this study, residential and commercial buildings were considered for the analysis and the measurements from Drone were validated with respective approved plans and manual inspections and showed positive results with threshold parameters like setbacks and height as per building bye-laws of Andhra Pradesh Government Order (G.O) 119. Based on the results, measurements from Drone are used for the buildings occupancy permissions following the State government building rules. This automated system would replace physical inspections and manual reports and significantly reduce costs and improve efficiency. As an important component in this pilot study, visualisation of the building information were represented / displayed on a web application in an interactive mode. This added value of UAV technology with an automated system in comparison with traditional ways provides geospatial information and can also be considered as an essential Earth Observation indicator which has the potential to lead to next generation Urban Information Services and in the Smart cities development. The considerable potential use of these indicators in urban planning and development offers an opportunity in appropriate decision making in day to day urban planning measures.
\end{abstract}

\section{INTRODUCTION}

\subsection{Background}

Urban decision making increasingly requires urban land-use and land-cover maps generated from very high spatial resolution data. Remote Sensing is well advanced in terms of technologies and methods like multi-sensor, multi-scale and multi-temporal analyses are primarily limited to roof top view of the buildings which represents an incomplete perspective of understanding the urban systems.

During the past 50 years, measurement technologies in surveying and engineering has made significant developments by introducing the surveying methods like Electronic Total Station (ETS), GPS, Robotic total station and laser scanner.

In recent years, the Unmanned Aircraft systems/UAVs/Drones have become the most advanced technology developed and a perfect platform for aerial photography, remote sensing studies, topographical surveys and mapping. These UAVs also make use of LIDAR and data derived from these active sensors capable of providing detailed 3D pint clouds from which detailed building structural information can be defined for urban planning and development measures. Many remote sensing and photogrammetry software packages are available, led by Leica, and drone data processing softwares like Drone Mapper, Photomodeler, Pix4D, Drone2Map from ESRIs platform, Agisoft Photoscan etc., can produce high resolution orthomosaics,3D information in accuracy that is equal to or better than conventional aerial photography. Standard GIS softwares and AutoCAD can be used to stitch and georeference drone aerial photos. Recent developments in Web based technologies using GIS; the drone derived outputs can be displayed by representing $2 \mathrm{D}$ and $3 \mathrm{D}$ information through webportals/dashboards.

Various building detection techniques have been reported during the last two decades like using algorithms in 2D and 3D information from photogrammetric imagery, integration of LIDAR and imagery for advance building detections, building heights and boundaries using LIDAR data. Recent break throughs in LIDAR (Hinks et. al., 2009) and UAV/Drone flight path planning which emphasizes building façade/footprint data capture, has greatly facilitated the potential for rapid autogeneration of $3 \mathrm{D}$ building models. However, the automatic building detection is still largely impeded by scene complexity, incomplete cue extraction and sensor dependency of data (Sohn and Dowman, 2007).Vegetation, and especially trees, can be the prime cause of scene complexity and incomplete feature extraction. Important building cues can be completely or partially missed due to occlusions and shadowing from trees 
(Awrangjeb et al., 2012). Goodwin et al., 2009 provided convincing examples of the use of small foot print in extracting building outlines and urban cover and structure information.

The present pilot study explains the technical methodology of Drone survey to extract building information and automatic report generation in the Andhra Pradesh Capital Region Development Authority (APCRDA) jurisdiction using UAVs.

\section{UAV / DRONE APPLICATION IN APCRDA}

In APCRDA, Planning department has implemented Andhra Pradesh Development Permission Management System (APDPMS) one of the major online building permission approval systems facilitating the automatic building permissions for the entire capital region as shown in Figure 1(a). It facilitates the integration of database from different departments like revenue data, registration, property tax, municipal properties/Govt. properties, Approved Layouts etc. As on today, as per building bye-laws of Andhra Pradesh Government Order (G.O) 119 a total of $\sim 79$ buildings were approved through the online system for occupancy issuance among \#93 with 4.3\% record of rejected buildings as shown in Figure 1(b).

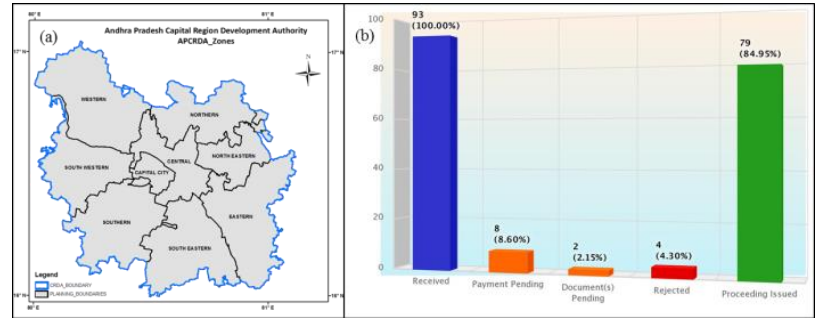

Figure 1: (a) Andhra Pradesh Capital Region Development Authority (APCRDA) jurisdiction (b) Statistics of Occupancy Building permissions through APDPMS

Currently, the Building approvals for Occupancy are taking place based on the traditional approach of site inspections using traditional surveying methods by taking manual measurements for the buildings. These traditional methods can be replaced by implementing the latest technologies like UAV/ Drone Surveys, from which the time \& cost for site inspections can be minimized from which accurate measurements can be obtained.

As a Pilot study, Drone survey method has been done in the APCRDA jurisdiction for constructed buildings greater than 500Square meters of site area which were under occupancy approval. Residential, Commercial, Public \& Semi-public and Industrial type of buildings were considered. The data acquired from UAV / Drone surveys were analysed and able to extract the building measurements like setbacks, dimensions/site area, building heights etc.from the UAV data.Along with the building measurements, Drone survey has also been done for construction monitoring in the high density urban areas which further helped in the identification of constructions made without approvals in monthly intervals as shown in Figure 2.

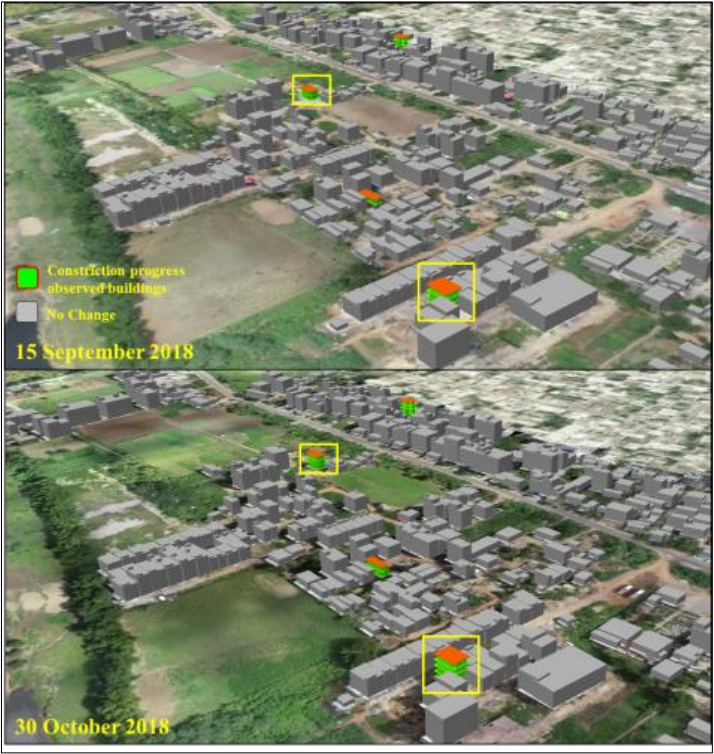

Figure 2: Construction monitoring in the dense urban area using drone survey at two time intervals.

\section{STUDY AREA}

The study sites were located randomly for the buildings under occupancy issuance in the Andhra Pradesh Capital Region Development Authority (APCRDA) jurisdiction which has been subdivided into 9 Zonal areas. A total of 78 buildings were surveyed using Drone technology as shown in the Figure 3(a). Figure 3(b) represents the \#2occupancy building sites considered for the analysis and comparison study.

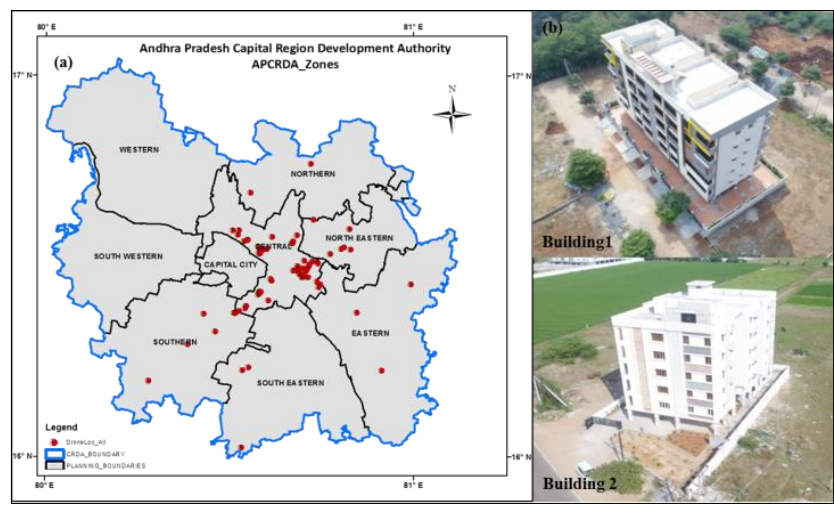

Figure 3: (a) Drone surveyed building locations (b) Buildings selected for the analysis

\section{METHODOLOGY}

The workflow of the pilot study was done by using the Unmanned Armed Vehicle DJI Phantom 4 pro to acquire all the aerial images. The entire methodology has been described as represented in the Figure 4. 


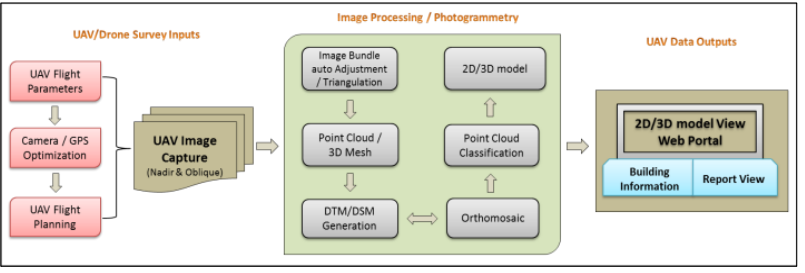

Figure 4: Flowchart representing automatic building information generation using UAVs/Drone

\subsection{UAVFlight Plan and Image Collection}

In regard to the UAV specifications, it is equipped with a built in camera and gimbal system.UAV carries a 1"CMOS sensor which captures 20 effective megapixel images.The aircraft with standard calibration method flies in a P-mode i.e., positioning mode which works best when the GPS signal is strong. The UAV utilizes GPS, stereo vision system and infrared sensing system to stabilize, avoid obstacles or track moving objects. The data collection by the UAV differs by the type of flight path. The grid mission is the best suited one to generate $2 \mathrm{D}$ maps from the images. The circular and double grid missions were designed to create 3D models of objects like buildings etc. As shown in Figure 5. Nadir view images (Figure 5(a)) were mostly used for the creation of Digital Terrain (or Surface) Models (Aicardi et al., 2016). As the information provided with the nadir images will not be sufficient to successfully capture

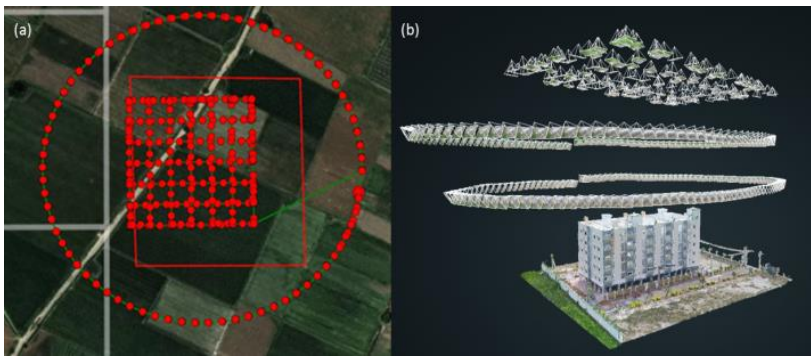

the details of the building facades. That is why oblique images (Figure 5(b)) were becoming more important in the UAV photogrammetric process by capturing the images without any overlap from end to end at a desired angle of $45^{\circ}$.

Figure 5: Data collection by using two flight plans (a) Double grid mission/linear mission (b) Circular mission

\subsection{Data Processing and Visualization}

The UAV collected raw RGB images were inserted to the cloud processing platform which uses photogrammetric image processing algorithms with $90 \%$ overlapping, low altitude and high resolution RGB imagery as an input, 3D point clouds, orthomosaic and 3D digital surface models were created. Traditional stereovision uses 2D images from multiple view angles to construct a 3D model as shown in Figure 4.

Prior to generating the orthomosaic, a 3D point cloud is generated. The main aim of process is to produce a georeferenced 3D point cloud by handling with overlapping aerial image data. The point cloud generated by using the captured images and can also be edited to remove any spurious points, which further used to view a $3 \mathrm{D}$ model, where all the dots of the point cloud are connected in order to create a surface. The mesh can contain artefacts, especially around the edges of the project where there will have been less image overlap. The mesh is useful to show the building sites looked like and it can be rotated and viewed from any angle; however, it should not be taken to be the visual truth and it is not a substitute for analysing the underlying images that created it.

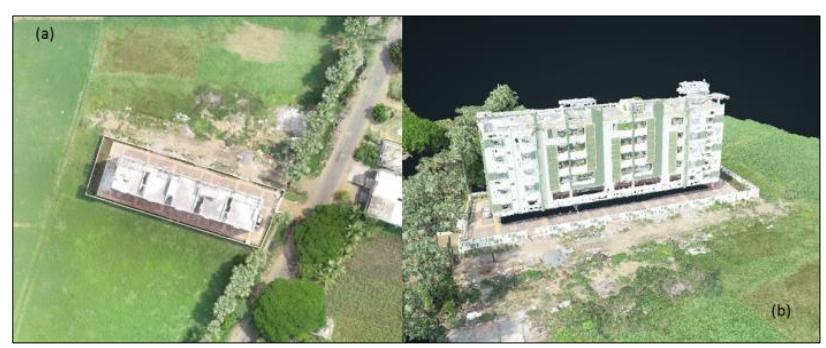

Figure 7: Building outputs generated after data processing(a) Orthomosaic image (b) 3D Building model

Point cloud data plays a significant role in various geospatial applications as it conveys plentiful information which can be used for different types of analysis. In the present study, using Potree (Potree, 2015), an open source WebGL point cloud render, the customized $2 \mathrm{D} \& 3 \mathrm{D}$ visualization portal named as 3rdi(Read as Third Eye) has been designed which supports level of detail point cloud rendering generated using UAV with an automatic report generation system.

Our experimental study demonstrated its performance by displaying the building models on GIS base maps, interactively

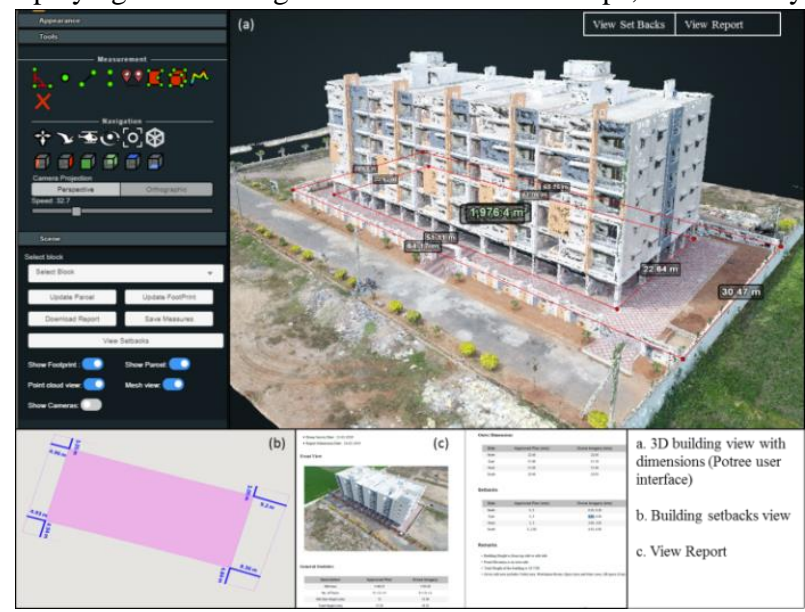

manipulating large building point cloud data sets such as rotating, scaling, extracting the building measurements of setbacks, height, dimensions etc. as shown in Figure 8.

Figure 8: Visualization web portal of the 3D building model

A Set Back tool has been developed in the customized viewer for setback measurements of the buildings (Figure 9) in order to minimize the errors and increase the accuracy. The automatic report generation has also been included in the visualization portal. 


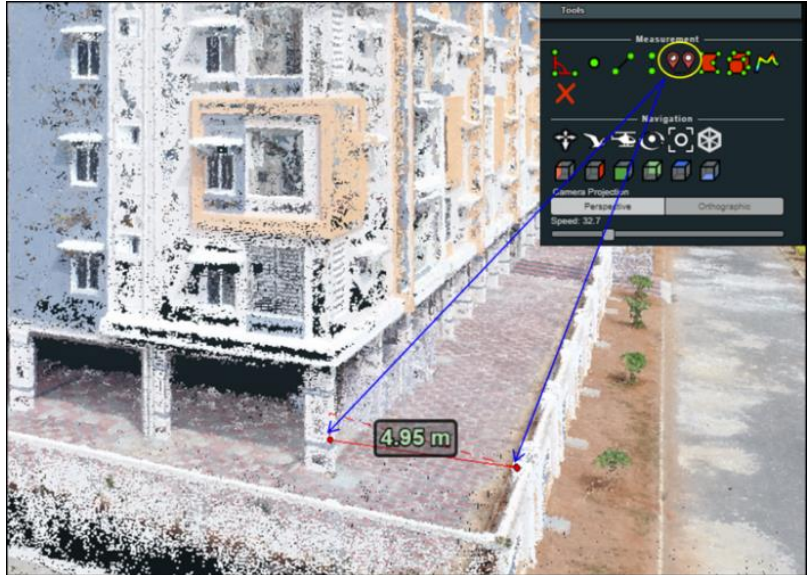

Figure 9: Setback measurement tool included in the 3D viewing webportal.

\section{EXPERIMENTAL RESULTS}

In this study, two residential building with varying extents were considered and the building measurements were taken as per the methodology explained. The results obtained from the drone imagery were compared with the approved/sanctioned plans as shown in the Figures 10 and 11. The data in Table 1 and Table 2 shows the positive differences from approved defined measurements and drone derived measurements which are in acceptable format as per the building rules and regulations of G.O 119. This explains that the deviation difference in the building setback measurements can be positive up to $10 \%$ which are acceptable. The positive differences may vary to each building type which again depends on the compound wall thickness, plantations etc.

If the deviation difference goes below $-10 \%$ i.e. the negative deviations are not acceptable. These are limited to the cases like architectural elevations, deviations in the plan to ground reality, physical obstacles, under construction works etc.

The differences calculated from the drone imagery data approved plans show reasonably promising results which demonstrate the potential and implementation of UAV based surveys in the urban development measures.

\subsection{Building-1}

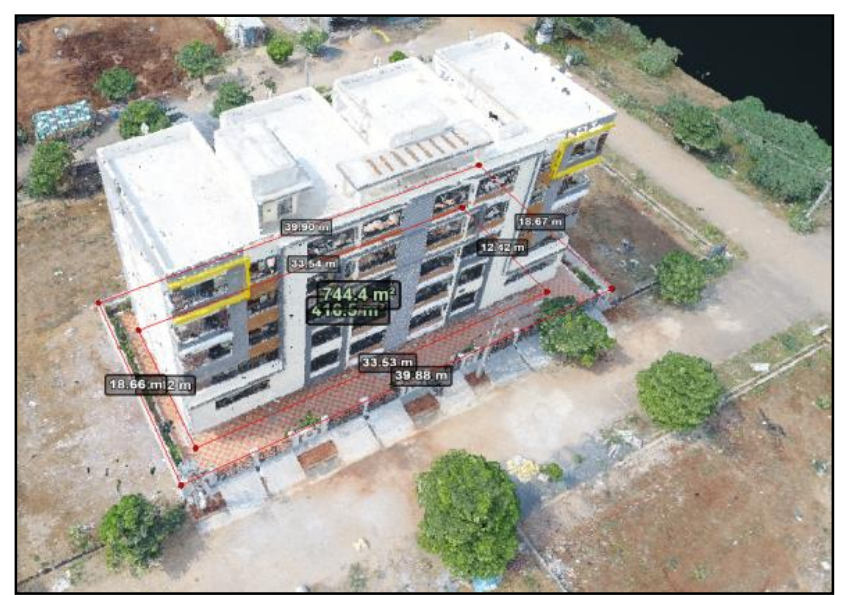

\begin{tabular}{|c|c|c|c|c|}
\hline \multicolumn{2}{|c|}{$\begin{array}{l}\text { Building } \\
\text { Parameters }\end{array}$} & $\begin{array}{c}\text { Approved } \\
\text { Plan } \\
\end{array}$ & $\begin{array}{c}\text { Drone } \\
\text { Imagery }\end{array}$ & Difference \\
\hline \multicolumn{2}{|c|}{ 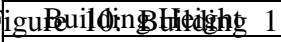 } & \multicolumn{3}{|c|}{ 3D difd foot pintl\&iew defl.4ed fro } \\
\hline \multicolumn{2}{|c|}{ DroneNo. of Floors } & $\mathrm{S}+\mathrm{G}+4$ & $\mathrm{~S}+\mathrm{G}+4$ & - \\
\hline \multicolumn{2}{|c|}{ Built-up area } & 410.60 & 416.42 & 5.82 \\
\hline \multirow{4}{*}{$\begin{array}{c}\text { Building } \\
\text { Dimensions }\end{array}$} & North & 12.39 & 12.42 & 0.03 \\
\hline & East & 33.14 & 33.53 & 0.39 \\
\hline & West & 33.14 & 33.54 & 0.40 \\
\hline & South & 12.39 & 12.42 & 0.03 \\
\hline \multirow{4}{*}{$\begin{array}{l}\text { Building } \\
\text { Setbacks }\end{array}$} & North & $4.60,4.60$ & $4.19,4.21$ & $0.41,0.39$ \\
\hline & East & 3,3 & $3.02,3.05$ & $0.02,0.05$ \\
\hline & West & $3.50,3.50$ & $3.22,3.18$ & $0.28,0.32$ \\
\hline & Sou & $2.50,2.50$ & $2.20,2.18$ & $0.30,0.32$ \\
\hline
\end{tabular}

Table 1: Building 1 measurements derived from Drone

\subsection{Building-2}



Figure 11: Building 2 3D and foot print view derived from Drone

\begin{tabular}{|c|c|c|c|c|}
\hline \multicolumn{2}{|c|}{$\begin{array}{c}\text { Building } \\
\text { Parameters }\end{array}$} & $\begin{array}{c}\text { Approved } \\
\text { Plan }\end{array}$ & $\begin{array}{c}\text { Drone } \\
\text { Imagery }\end{array}$ & Difference \\
\hline \multicolumn{2}{|c|}{ Building Height } & 15 & 15.38 & 0.38 \\
\hline \multicolumn{2}{|c|}{ No. of Floors } & S+G+4 & S+G+4 & - \\
\hline \multicolumn{2}{|c|}{ Built-up area } & 1148.27 & 1155.95 & 7.65 \\
\hline \multirow{4}{*}{$\begin{array}{c}\text { Building } \\
\text { Dimensions }\end{array}$} & North & 22.48 & 22.64 & 0.16 \\
\cline { 2 - 5 } & East & 51.08 & 51.10 & 0.02 \\
\cline { 2 - 5 } & West & 51.08 & 51.04 & 0.04 \\
\cline { 2 - 5 } & South & 22.48 & 22.63 & 0.15 \\
\hline \multirow{3}{*}{$\begin{array}{c}\text { Building } \\
\text { Setbacks }\end{array}$} & North & 5,5 & $5.36,5.20$ & $0.36,0.2$ \\
\cline { 2 - 5 } & East & 5,5 & $4.84,4.94$ & $0.5,0.06$ \\
\cline { 2 - 5 } & West & 3,3 & $3,3.05$ & $0,0.05$ \\
\cline { 2 - 5 } & South & $5,2.50$ & $4.93,4.96$ & $0.07,2.46$ \\
\hline
\end{tabular}

Table 2: Building 2 measurements derived from Drone

\section{CONCLUSIONS}

In this research we evaluated the use of a UAV platform for urban applications and the experimental results demonstrated it's potential. This is the first of its kind pilot study that has been taken up in the APCRDA jurisdiction for the urban egovernance and smart city development applications. 
$\mathrm{UAV}$ as an alternative platform for 3D point cloud acquisition offers potentials because of its flexibility and practicability combined with low cost of implementations. Along with the building feature detection techniques, the drones are very much useful in identification of the unauthorized constructions, building construction monitoring, and land developments. There are some limitations that should be taken into account in the UAV data processing. To fully implement the UAV platform as a suitable tool for urban applications, technological advances in RTK mode UAVs provide much higher accuracy of the UAVs location and improvements of sensors will also increase the spatial accuracy. With the current advancement in recent technologies, utilization and implementation of UAVs in urban planning and development also useful for smart city development and provide an opportunity for appropriate decision making in day to day urban planning measures.

\section{ACKNOWLEDGEMENTS}

Our sincere thanks to the XYZ Innovations Private Limited team for the technical support to carry out the Drone survey.

\section{REFERENCES}

Aicardi, I., Chiabrando, F., Grasso, N., Lingua, A. M., Noardo, F., Spano, A., 2016. UAV Photogrammetry with Oblique Images: First Analysis on Data Acquisition and Processing. ISPRS International Archives of the Photogrammetry, Remote Sensing and Spatial Inf. Sci., XLI-B1, 835-42.

Andhra Pradesh Development Permission Management System, Andhra Pradesh, India, 2016. http://apdpms.ap.gov.in

APGOMS No. 119 MAUD (M) Department: AP Buildings rules dated 28.03.2017. https://goir.ap.gov.in.

Awrangjeb, M. and Fraser, C. S., 2012. An automatic and threshold-free performance evaluation system for building extraction techniques from airborne LIDAR data. IEEE Journal of Selected Topics in Applied Earth Observations and Remote Sensing, 7(10), 4184-4198.

Goodwin, N. R., Coops, N. C., Tooke, T. R., Christen, A. Voogt, J. A., 2009. Characterizing urban surface cover and structure with airborne LiDAR technology. Canadian Journal of Remote Sensing, 35(3), 297-309.

Hinks, T., Carr, H., Laefer, D. F., 2009. Flight optimization algorithms for aerial LiDAR capture for urban infrastructure model generation. Journal of Computing in Civil Engineering, 23(6), 330-9.

https://www.dji.com/phantom-4-pro/info\#downloads

Potree, 2015. http://www.potree.org/.

Sohn, G. and Dowman, I., 2007. Data fusion of high-resolution satellite imagery and LIDAR data for automatic building extraction. ISPRS Journal. 